\title{
The Impact of Poverty on the Environment: Surprising Findings from the Indian Case
}

\author{
Siddhartha Mitra ${ }^{1} \&$ Raadhika Paul ${ }^{2}$ \\ ${ }^{1}$ Department of Economics, Jadavpur University, India \\ ${ }^{2}$ Department of Economics, University of Calcutta, India \\ Correspondence: Siddhartha Mitra, Department of Economics, Jadavpur University, India. E-mail: \\ mitsid@yahoo.com \\ Received: September 14, 2018 \\ Accepted: October 11, 2018 \\ Online Published: October 20, 2018 \\ doi:10.5539/ijef.v10n11p51 \\ URL: https://doi.org/10.5539/ijef.v10n11p51
}

\begin{abstract}
In the 1980s a powerful school of thought, propagated by the Brundtland Commission Report and seconded by powerful think tanks, developed which asserted that poverty was a major cause for environmental degradation. This implied that significant alleviation of poverty would also substantially reduce environmental degradation. Some reasons were given for this view, prominent among these being the compulsion of poorer households to mine natural capital to meet their needs, sometimes in a dirty manner. In course of time, a less recognized counter-school emerged which pointed out the flaws in the Brundtland hypothesis: the greater gasoline consumption of richer households, their greater possession of consumer durables sourced from natural capital, and the higher power of the rich to mine limited and open access natural capital for commercial gain, among others. The debate needs to be obviously resolved through quantitative studies, hitherto lacking in the Indian case. Using results from NSSO data for 3 recent years and 4 sources of dirty fuel we show that there is a general tendency for the non-poor to consume more of these fuels than the poor. This is a surprising result and it shows that poverty alleviation, though desirable, is probably not even a partial cure for environmental degradation. Some explanations for this result, based on the relative magnitudes of clean fuel consumption by the non-poor and poor, are provided.
\end{abstract}

Keywords: poverty, environmental degradation, natural capital, dirty fuels

\section{Introduction}

The predominant view in the academic and policy literature about the relationship between poverty and environmental degradation is that a greater incidence of poverty enhances environmental degradation. The direct policy implication of this school of thought is that poverty alleviation is at least a significant part of the solution to environmental degradation.

The foundations of this school of thought were laid by the Brundtland Commission Report (1987) which is considered as the blueprint for environmental conservation (Duraiappah, 1996). The views of this school have been propagated by international think tanks or their representatives: for example, Jalal (1993), the then chief executive of the Asian Development Bank, the World Bank through its World Development Report (1993), and finally the United Nations Environment Programme (1995).

These agencies of course offer valid reasons for supporting this school of thought: since the poor lack income and wealth they mine natural capital such as forests and trees to meet their needs and deplete the soil of its nutrients during farming. Further, it is argued that they often use pollution intensive fuels such as firewood and plant matter collected from forests and woodlands instead of clean fuels such as Liquefied Petroleum Gas (LPG) which only the non-poor can afford.

One of the early criticisms of the Brundtland School came from Reardon and Vosti (1995) who argued for a more nuanced approach for analysing the impact of poverty on environmental degradation. For example, in certain cases, poor people may be forced to move to the cultivation of fragile hillsides to raise a livelihood. This might prevent soil erosion which impacts the environment positively. In other cases, they may be forced to seek refuge in forests to meet their needs with negative ramifications for the environment. Second, the magnitude of the community's wealth and the distribution of poverty within the community affect the effectiveness with which the 
poor manage natural resources. Scherr (2000) also emphasizes the variable link between poverty and environment, especially because the poor have an unrecognized potential for adaptation and innovation which can be leveraged suitably through public policy.

It can also be argued that the Brundtland view does not take account of quite a few other ways in which human behaviour affects the environment, which detracts from the picture it forms of the relative impacts of the poor and non-poor on the environment. For instance, this view neglects the fact that much of the wealth of the non-poor such as consumer durables - for example, furniture and appliances - is embodied natural capital. Even demand for consumer non-durables such as animal products (milk and meat) and gasoline, which is higher among the non-poor, is a cause of significant environmental degradation.

For example, modern levels of supply of milk and meat observed in developed countries are only possible through industrialized animal rearing techniques which cause large amounts of air polluting methane emissions. A study conducted by Williams et al. (2006) shows that the greenhouse gas (GHG) emissions per annum due to livestock consumption in the United Kingdom at the time of the study were 57.5 million tonnes of $\mathrm{CO}_{2}$ equivalent. The method used to arrive at this estimate was to calculate emissions per unit weight (kilogram) of consumed livestock and multiply this by the amount of livestock consumed. The first of these factors can be assumed to be a parametric constant. Therefore, we can assume that emissions of GHG - per capita or in a country as whole -- caused by consumption of livestock increases in proportion to the magnitude of that consumption.

In 2006 the population in the United Kingdom was 61 million (Office for National Statistics, UK). This implies that the annual emission per capita due to livestock consumption was 0.94 tonnes, a very significant amount. Note that a majority of the poor in the world live in the low or low middle income countries/regions of Bangladesh, India, Pakistan and Sub Saharan Africa (SSA). In spite of the vast cultural diversity within this group, meat consumption (beef, pig, poultry and sheep) per capita per annum in 2006, according to OECD data, varied from 3 and $3.1 \mathrm{~kg}$ per annum in Bangladesh and India respectively to 8.31 and 10.96 in SSA and Pakistan respectively. These figures are extremely low when compared to the averages for the distinctly more affluent OECD and EU28 group of countries, both of which contain the United Kingdom, of 67.03 and $66.8 \mathrm{~kg}$ respectively. These figures broadly illustrate the tendency for meat consumption per capita to go up with increase in income and decline in poverty. An obvious implication is that GHG emission per capita due to livestock consumption increases significantly with both per capita income increase and poverty alleviation. This relationship encapsulates the propensities observed in the recent past. It is possible that creation of awareness among the wealthy in regard to the generation of GHG emission through livestock consumption might actually curb their consumption to such an extent such that the observed relationship would not be valid in the distant future.

Similarly, a greater consumption of gasoline also has adverse impacts. It leads to a faster depletion of the limited and precious fossil fuel stock (Duraiappah, 1996) (Note 1) as well as climate change through GHG emissions, and local air pollution. The data for gasoline consumption per capita by country in 2016 (GlobalPetrolPrices.com) again shows the tendency for such consumption to go up with income and down with incidence of poverty though for similar levels of per capita income, population density does play a very important role. For example, the USA with 4.39 liters of gasoline consumption per capita per day followed by various Arab countries, Luxembourg, Canada and Australia, at above 2 liters, are members of the 'top 10' in regard to gasoline consumption per capita. This top 10 consists entirely of high income countries, with nine of these having a per capita income (Note 1) in excess of \$37,000 per annum in 2017 and only Libya having a per capita income which is much lower at $\$ 17,882$. Six of these countries - USA, Saudi Arabia, Oman, Canada, Australia and Libya - have a population density (Note 2) of less than 35 persons per square $\mathrm{km}$, with the last three having a density of less than 4 persons. Apart from Libya their incomes fall in the range of $\$ 37,500-\$ 55000$. The other (four) countries in the top ten - Kuwait, Brunei, Luxembourg and Qatar - however have much higher population densities in the range of $79-210$ persons per square $\mathrm{km}$. In spite of their higher population densities, gasoline consumption per capita is high in these countries due to their extremely high per capita incomes in the range of $\$ 65,500-117,000$. European countries such as United Kingdom (0.80 liters per capita per day), Germany (0.84) and France (0.44), each with a per capita income in the range of $\$ 38,000-46,000$ in 2017 but with a density of population (264.94, 120.59 and 231.31 respectively) much greater than the levels observed in the mentioned group of six in the 'top 10'with comparable per capita incomes, are characterized by much more moderate levels of per capita gasoline consumption.

As in the case of livestock, countries characterized by a high level of poverty and low level of per capita income exhibit the lowest per capita consumption levels of gasoline which are very small even compared to the 
mentioned European countries: Ethiopia (0.01 liters), Bangladesh (0.01), India (0.05), Pakistan (0.07) and Nigeria (0.17). Much of the variation in per capita consumption levels within this group is possibly explained by the density of population though variation in per capita income still plays a significant role. For example, Bangladesh (per capita income of $\$ 3,524$ and 1203 persons per square $\mathrm{km}$ ) is much more densely populated than more affluent India ( $\$ 6,427$ and 421 persons) which in turn has a density which greatly exceeds that of Pakistan $(\$ 5,035$ and 236) and Nigeria $(\$ 5,338$ and 190$)$. Ethiopia $(\$ 1,730)$ has a per capita consumption equal to that of Bangladesh as the consumption enhancing effect of a lower population density in the case of Ethiopia is neutralized by its much lower per capita income.

The comparisons made above can be used to make the following argument: just as countries characterized by a higher level of per capita income and lower level of poverty are seen to consume more livestock and gasoline per capita, even within developing countries the poor consume less of these items per capita than the non-poor. Therefore, the poor generate lower GHG emissions per capita through these channels as compared to the non-poor. Hence poverty alleviation is expected to lead to an increase in GHG emissions through this channel. We now look at household level data at the level of a country to see whether these conclusions drawn from macroeconomic evidence are supported.

Indian National Sample Survey data highlight how much more of meat the rich consume as compared to the poor. Rukmini and Sivaraman (2014) use this data for 2011-12 to show that the richest 5\% among urban dwellers consumed as much as $13.7 \mathrm{~kg}$ of meat per capita per year whereas the poorest $5 \%$ consumed $2.4 \mathrm{~kg}$ per capita. The corresponding figures for rural areas are 17.4 and 1.56 respectively, highlighting an even bigger difference between the rich and the poor.

Variation of gasoline consumption with income has not been, to our knowledge, studied that carefully for India though such variation in consumption with respect to expenditure in the case of LPG and electricity has been discussed in detail later in the paper. However, Rodriguez-Oreggia and Yepez-Garcia (2014) do a careful study of gasoline consumption across the income distribution for Mexico, a developing country like India, based on micro data from Mexican Expenditure surveys. Using data for 2010 they show that average household consumption of gasoline increases significantly in both rural and urban areas with movement from each income decile to the next with the rate of increase showing a marked enhancement from the $8^{\text {th }}$ decile onwards. The average household consumption for the $10^{\text {th }}$ decile is more than 7 times that for the $3^{\text {rd }}$ decile in both rural and urban areas. .For the bottom decile average household consumption is negligible.

The evidence above, for both households in the national income distribution and aggregated at the level of nations, points to the upward push that poverty alleviation and increase in per capita income can give to GHG emissions through two significant sources for such emissions, consumption of livestock and use of gasoline.

Next we address the question of how natural capital such as forests yielding firewood and plant matter, and rivers and lakes are affected by the incidence of poverty. Note that all of these are open access resources waiting to be harvested by anybody and everybody. While it can be argued that the poor need these products more than the non-poor the latter are much better at harvesting these scarce resources and converting them into marketable goods because of access to mechanized means of extraction. The 'open access' nature of these resources can be expected to lead to a race to the bottom with the rich successfully outracing the poor to extract these resources, the former intent on commercial exploitation and the latter driven by their needs.

It must be realized that the urban poor are in an even more disadvantaged position in regard to exploiting the environment as compared to the rural poor: they do not have the same access to the natural environment as embodied by forests, woods and water bodies and therefore do not possess the same ability to mine these. As consumption is constrained by incomes they turn to environmentally sustainable practices such as scrap collection and rag picking to make ends meet. Such behaviour is noticed all over the developing and developed world (see Furedy, 1984 for the city of Calcutta, now Kolkata; Medina, 2001 for the United States; and Medina, 2000 for the Asian and Latin American cases).

Sattherthwaite (2003) highlights certain other reasons for the validity of the counterview to the Brundtland School in the case of developing countries: unregulated industrialization driven by the rich contributing to pollution of air and water; and higher incomes being associated with greater generation of waste which enhances soil pollution directly and air pollution indirectly when it is burnt. Analogously, wealthy farmers exploit their greater access to financial resources to use chemical fertilizers more intensively than poor farmers with serious ramifications for the environment (Reardon \& Vosti, 1995).

The analysis above, both quantitative and qualitative, strongly indicates that degradation of the environment by the non-poor through many of the known channels is greater than that by the poor. However, the Brundtland 
School's claim that the poor rely mainly on dirty fuels while the non-poor consume mainly clean fuels continues to lend ambiguity to the relationship between poverty and environmental degradation. If this claim is substantiated by empirical evidence then one can argue that greater incidence of poverty indeed tends to enhance a significant component of atmospheric pollution, with grave implications for the environment. This paper tries to check the empirical validity of this claim in the Indian case. This constitutes a significant study as India accounts for more than one-sixth of the world's population -- i.e. 1.31 billion out of a global total of 7.38 billion in 2015 (United Nations, 2017) -- and is characterized by a significant incidence of poverty, thereby implying that in terms of magnitude the environmental implications of poverty alleviation in India would constitute a very significant portion of those of poverty alleviation in the world.

The objective of this paper is to obtain a precise idea about how environmental degradation augmenting consumption of certain natural resources -- firewood, coal, charcoal and coke - which constitute 'dirty fuels' varies across the poor and non-poor in rural and urban India. By looking at how such consumption varies with an upward movement along the income/expenditure ladder we can determine whether poverty enhances environmental degradation -- in this case in terms of the atmospheric environment, both indoor and outdoor, as well as depletion of the natural resource base. The results are better appreciated by also looking at access of the poor and non-poor population in rural and urban areas to clean fuels such as LPG and electricity which are very effective substitutes for dirty fuels. The methodology for this quantitative analysis and the relevant data sources are explained in Section 2. The results are presented in Section 3. Section 4 is devoted to conclusions which include explanations of our findings, recommendations for further research on the theme of the paper so as to gain deeper insights into the relationship between poverty and the environment, as well as policy recommendations emerging from our results.

The significance of the environmental implications of poverty alleviation in India is best illustrated by some estimates. The estimation of poverty carried out by the Government of India using two different but robust methodologies led to significantly different estimates of poverty, $21.9 \%$ and $29.5 \%$, for 2011-12 (Planning Commission, 2014). Using population estimates for 2011 generated by United Nations (2017) and the lower of the two estimates of percentage poverty incidence in India we arrive at an estimate of 273.75 million poor people in India in 2011-12, which on its own accounted for 3.9\% of the total world population of 7.04 billion. Unfortunately, we cannot express this estimate of the number of poor people in India as a percentage of the world's population of poor people since the estimation methodology used by the Planning Commission of India has not been used to identify the poor in other countries. Very recently, though, a methodology for computing the number of people in extreme poverty all over the world has been developed (Cuaresma et al., 2018). This methodology has given rise to the World Poverty Clock (referenced) which is available online. This shows that in January 2016, 145.7 million people lived in extreme poverty in India, the definition of an extremely poor person being one who lives on less than the U.S purchasing power equivalent of 1.9 dollars in 2011. The Indian population of extremely poor people in January 2016 equalled as much as $20 \%$ of the estimated 726.8 million people living in extreme poverty. An article by Kharas, Hamel and Hofer (2018) illustrates the extremely fast rate of extreme poverty alleviation in India. A quantification of the extremely fast decline is obtained by consulting the World Poverty Clock which has been constructed by these very authors: in one year starting January 2016, the number of extremely poor people in the world declined by 33.7 million whereas that in India declined by 35.4 million. In other words, the Indian decline was more than the global decline, a phenomenon made possible by increase in the number of extremely poor people in other countries such as some countries in SSA.

The large number of people in poverty and extreme poverty in India and the reported fast rate of alleviation of such poverty imply that the environmental implications of poverty alleviation in India are huge in the global context, provided that the difference between the per capita impacts on the environment of the poor and non-poor are significantly different.

\section{Methodology and Data Sources}

We use data from the National Sample Survey for India for the years 1987-88, 1999-00 and 2011-12 as tabulated by Ranjan and Singh (2017) for the purpose of studying energy poverty, but process this data further to arrive at our own tables. One category of fuels covered by this data tabulation consists of 'dirty fuels', namely firewood, coal, charcoal and coke, which are, allegedly, consumed more by the poor because of their low wealth/incomes. Such presumed overconsumption forms much of the basis for the Brundtland argument that poverty enhances environmental degradation. The other studied category consists of 'clean fuels' such as LPG and electricity which the poor often cannot afford but are consumed by the non-poor. 
Ranjan and Singh's data provides per capita consumption of each of the mentioned fuels for various expenditure quintiles of households. We bunch these quintiles into 'poor households' and 'non-poor households' with the former referring to the first two quintiles and the latter to the next three quintiles. This allows us to obtain cleaner results as the categories of households are reduced in the process of bunching from 5 to 2 , thus eliminating the problem of non-monotonicity in fuel consumption on movement along the income/expenditure ladder which makes analysis difficult. We obtain the magnitudes of rural and urban per capita consumption by the non-poor and the poor of each fuel in each studied year. Table 4 displays these magnitudes.

However, one has to recognize that average household size varies across the mentioned quintiles. Thus, the average household size for each quintile has to be used to construct appropriate weights to obtain the per capita consumption of each fuel in the 'poor' and 'non-poor' population categories. For example, assume that $f_{i}$ is the per capita fuel consumption in expenditure quintile $i$ of households and that average household size in that quintile is given by $h_{i}$. The per capita fuel consumption of 'poor' and 'non poor' populations is then given by

$\frac{\sum_{i=1,2} f_{i} h_{i}}{\sum_{i=1,2} h_{i}}$ and $\frac{\sum_{i=3,4,5} f_{i} h_{i}}{\sum_{i=3,4,5} h_{i}}$ respectively.

We use data from the World Health Survey, 2003 conducted by the WHO (2003) to construct the above weights. The WHO carried out this survey to describe the health situation in 27 countries and identify the policy and implementation gaps which needed to be fixed. The survey of the Indian case in 2003 was based on a random and stratified sample of 10,279 households which was large enough to be representative. The results of this survey are therefore reliable.

This data source shows that average household size in India increases with per capita income of the household (see Table 1). One would generally expect household size to be declining as we move up the income distribution of households because of richer families having a lower number of children. However, the WHO data is collected from de jure residents of a household i.e. those members of the household who reside in the registered residence of the household for most part of the year. Note that many of the adult members affiliated to rural poor households migrate to cities for the purpose of earning their livelihoods. Similarly, urban poor households can often be small because these are formed out of members of rural households who have migrated to cities. It is likely that this is the reason Table 1 shows that the average number of members per household is lower among poorer households.

Table 1. Household sizes by income quintile and poverty status for the entire population

\begin{tabular}{cccc}
\hline Quintile & Household Size & Category & Household size by category \\
\hline 1 & 5.5 & Poor & 5.75 \\
2 & 6 & & \\
3 & 6.6 & Rich & \\
4 & 6.8 & & \\
5 & 6.5 & & \\
\hline
\end{tabular}

Source: Report of India (http://www.who.int/healthinfo/survey/whsind-india.pdf), World Health Survey, WHO (2003).

Additionally, for each of the studied fuels, the ratio between the per capita non-poor and poor consumption is computed for each of the studied years. Thus, we not only come to know whether the per capita fuel consumption in the case of the poor is greater or less than that of the non-poor in each year we also obtain a precise idea of the relative magnitudes of the per capita fuel consumption of the non-poor and the poor in each year and therefore the trends over time.

Table 1 is also used to process the data from Ranjan and Singh (2017) to work out average household fuel consumption for each expenditure quintile, as recorded in Table 3. Note that this exercise as well as that of computing per capita consumption of each fuel for 'poor' and 'non-poor' populations is based on the data for average household size by income class for India as a whole. Given that Ranjan and Singh's data are for expenditure quintiles in rural and urban India, the implicit assumption made in our computation is that the Indian household size distribution by income quintile matches with that by expenditure quintile, and that the distributions of the former type for rural and urban areas are not significantly different from each other and therefore from the country as a whole. 


\section{Results}

Table 2 presents the data from Ranjan and Singh (2017) on consumption of dirty fuels but in a slightly different format. It shows that in the case of both rural and urban India, the hypothesis that the poor consume more dirty fuel than the rich is manifestly not true. The per capita consumption of firewood shows a monotonic increase with a movement up the expenditure ladder in both rural and urban areas in all the studied time periods. In regard to coal, the per capita consumption in the terminal year in rural areas either increases or remains constant as we move from one quintile to the next whereas in urban areas in the initial year it shows a monotonic increase. Given that our study relates to consumption of 4 fuels for 3 years in rural and urban areas separately, it can be considered as covering 24 cases. Out of these 7 cases reveal strictly monotonic increase on movement up the expenditure ladder, 1 case exhibits weak monotonic increase, and the other 16 cases reveal the absence of a monotonic relationship. In short, there is some evidence against the Brundtland hypothesis. However, the division of the population into 5 quintiles means that there is more than 1 quintile belonging to the class of the non-poor for sure and also possibly for the poor, given the estimated rates of Indian poverty incidence of $21.9 \%$ and alternatively 29.5\% in 2011-12 mentioned in Section 1. Further, the fine division of the household population into 5 quintiles leaves a lot of scope for non-monotonic behaviour of fuel consumption with expenditure and therefore for ambiguity in findings.

As described in Section 2, Table 3, which gives the average per household fuel consumption by expenditure class, is constructed by processing the data in Table 2 using the data on household size by income class presented in Table 1 . The 8 cases of monotonic increase in per capita consumption on upward movement along the expenditure ladder, mentioned in the last paragraph, repeat themselves; in addition there are three more cases of monotonic increase, that for coke in the initial years for both rural and urban areas and for coal in the middle year for urban areas. In short, there are 11 cases of monotonic increase and 13 cases of non-monotonic behaviour.

However, the problem of non-monotonic behaviour is avoided if we classify the bottom two quintiles as 'poor' and the top three quintiles as 'non-poor'; and then work out per capita consumption of each fuel in 'poor' and 'non-poor' populations by using the average household sizes in the five income quintiles for India as a whole, as described in Section 2.

With three time periods and four types of fuels we get 12 comparisons each of per capita consumption of 'dirty fuel' by the 'poor' and 'non-poor' in rural and urban India from Table 4. As many as 11 out of 12 cases each in rural as well as urban areas show the poor consuming less of the dirty fuel, thus contradicting the Brundtland type hypothesis of poverty enhancing dirty fuel consumption. The lone exceptions are coke in 2011-12 in the case of rural areas and charcoal in 1999-00 in the case of urban areas.

Table 2. Expenditure quintile wise per capita consumption ( $\mathrm{kg} / \mathrm{month})$ of dirty fuels across time in rural and urban India (Quintile 1 is the poorest quintile)

\begin{tabular}{|c|c|c|c|c|c|c|}
\hline \multirow[b]{2}{*}{ Quintile } & \multicolumn{3}{|c|}{ Rural } & \multicolumn{3}{|c|}{ Urban } \\
\hline & 1987-88 & 1999-00 & 2011-12 & $1987-88$ & 1999-00 & $2011-12$ \\
\hline \multicolumn{7}{|c|}{ FIREWOOD } \\
\hline 1 & 14.6 & 16.3 & 19.5 & 11 & 12.5 & 14.8 \\
\hline 2 & 17.5 & 19.1 & 23.1 & 13.1 & 14.6 & 16.2 \\
\hline 3 & 20.2 & 22.2 & 25.7 & 15.4 & 15.9 & 16.8 \\
\hline 4 & 22.5 & 25 & 26.7 & 17.3 & 17.5 & 17.8 \\
\hline 5 & 28.5 & 28.3 & 28.7 & 19.6 & 19.3 & 19.9 \\
\hline \multicolumn{7}{|c|}{ CHARCOAL } \\
\hline 1 & 4.5 & 3.7 & 3.8 & 3.1 & 6 & 2.9 \\
\hline 2 & 4 & 1.1 & 3.1 & 5.8 & 5.1 & 3.3 \\
\hline 3 & 6.4 & 3.1 & 4.8 & 4.2 & 3.7 & 3.5 \\
\hline 4 & 4.5 & 4.6 & 3.7 & 4.8 & 4.7 & 2.9 \\
\hline 5 & 6.6 & 7.7 & 4.3 & 5.9 & 3.8 & 4.2 \\
\hline \multicolumn{7}{|c|}{ COKE } \\
\hline 1 & 13 & 10.5 & 16.2 & 7.7 & 8 & 12.3 \\
\hline 2 & 14.2 & 14.3 & 10.3 & 9.4 & 11.1 & 11.5 \\
\hline 3 & 14 & 13.8 & 8.5 & 10.8 & 12.6 & 14.6 \\
\hline 4 & 15.3 & 16.8 & 15.9 & 11.6 & 16.8 & 11.7 \\
\hline 5 & 17.6 & 16.8 & 6.4 & 15.6 & 15.4 & 8.3 \\
\hline
\end{tabular}




\begin{tabular}{lllllll}
\hline \multicolumn{7}{c}{$\boldsymbol{C O A L}$} \\
\hline 1 & 7.1 & 11 & 9.3 & 7.1 & 13.6 & 10.5 \\
2 & 10.8 & 13 & 9.7 & 10.2 & 12.4 & 12.6 \\
3 & 12.8 & 12 & 13.9 & 11.6 & 14.4 & 12.8 \\
4 & 12.0 & 15.2 & 13.9 & 12.4 & 15.1 & 15.9 \\
5 & 16.7 & 16.6 & 21.6 & 18.3 & 21.0 & 13.4 \\
\hline
\end{tabular}

Source: Ranjan and Singh (2017).

Table 3. Expenditure quintile wise consumption per household (kg / month) of dirty fuels across time in rural and urban India (Quintile 1 is the poorest quintile)

\begin{tabular}{|c|c|c|c|c|c|c|}
\hline \multirow[b]{2}{*}{ Quintile } & \multicolumn{3}{|c|}{ Rural } & \multicolumn{3}{|c|}{ Urban } \\
\hline & 1987-88 & 1999-00 & 2011-12 & $1987-88$ & 1999-00 & 2011-12 \\
\hline \multicolumn{7}{|c|}{ FIREWOOD } \\
\hline 1 & 80.3 & 89.7 & 107.3 & 60.5 & 68.8 & 81.4 \\
\hline 2 & 105 & 114.6 & 138.6 & 78.6 & 87.6 & 97.2 \\
\hline 3 & 133.3 & 146.5 & 169.6 & 101.6 & 104.9 & 110.9 \\
\hline 4 & 153 & 170 & 181.6 & 117.6 & 119 & 121 \\
\hline 5 & 185 & 184 & 186.6 & 127.4 & 125.5 & 129.4 \\
\hline \multicolumn{7}{|c|}{ CHARCOAL } \\
\hline 1 & 24.8 & 20.4 & 21 & 17.1 & 33 & 16 \\
\hline 2 & 24 & 6.6 & 18.6 & 34.8 & 30.6 & 19.8 \\
\hline 3 & 42.2 & 20.5 & 31.7 & 27.7 & 24.4 & 23.1 \\
\hline 4 & 30.6 & 31.28 & 25.2 & 32.6 & 32 & 19.7 \\
\hline 5 & 42.9 & 50.1 & 28 & 38.4 & 24.7 & 27.3 \\
\hline \multicolumn{7}{|c|}{ COKE } \\
\hline 1 & 71.5 & 57.8 & 89.1 & 42.4 & 44 & 67.7 \\
\hline 2 & 85.2 & 85.8 & 61.8 & 56.4 & 66.6 & 69 \\
\hline 3 & 92.4 & 91.1 & 56.1 & 71.3 & 83.2 & 96.4 \\
\hline 4 & 104 & 114.2 & 108.1 & 78.9 & 114.2 & 79.6 \\
\hline 5 & 114.4 & 109.2 & 41.6 & 101.4 & 100.1 & 54 \\
\hline \multicolumn{7}{|c|}{ COAL } \\
\hline 1 & 39.1 & 60.5 & 51.2 & 39.1 & 74.8 & 57.8 \\
\hline 2 & 64.8 & 78 & 58.2 & 61.2 & 74.4 & 75.6 \\
\hline 3 & 84.5 & 79.2 & 91.7 & 76.6 & 95 & 84.5 \\
\hline 4 & 81.6 & 103.4 & 94.5 & 84.3 & 102.7 & 108.1 \\
\hline 5 & 108.6 & 107.9 & 140.4 & 119 & 136.5 & 87.1 \\
\hline
\end{tabular}

Source: Computed using Table 1 and 2.

Table 4. Average per capita consumption ( $\mathrm{kg} / \mathrm{month})$ of dirty fuels by the poor and non-poor in rural and urban India across time

\begin{tabular}{lcccccc}
\hline & \multicolumn{7}{c}{ RURAL } & URBAN \\
\cline { 2 - 7 } & $1987-88$ & $1999-00$ & $2011-12$ & $1987-88$ & $1999-00$ & $2011-12$ \\
\hline Poor & 16.11 & 17.76 & 21.38 & 12.10 & 13.60 & 16.11 \\
Non-poor & $23.70(1.47)$ & $25.15(1.42)$ & $27.02(1.26)$ & $17.42(1.44)$ & $17.56(1.29)$ & $23.70(1.47)$ \\
\hline \multicolumn{7}{c}{ CHARCOAL } \\
\hline Poor & 4.24 & 2.34 & 3.43 & 4.51 & 4.24 \\
Non-poor & $5.82(1.37)$ & $5.12(2.19)$ & $4.26(1.24)$ & $4.96(1.1)$ & $4.07(0.74)$ & $5.82(1.37)$ \\
\hline \multicolumn{7}{c}{ COKE } \\
\hline Poor & 13.63 & 12.48 & 13.12 & & 13.63 \\
Non-poor & $15.62(1.15)$ & $15.81(1.27)$ & $10.34(0.79)$ & $12.64(1.47)$ & $14.95(1.55)$ & $15.62(1.15)$ \\
\hline \multicolumn{7}{c}{ COAL } \\
\hline Poor & 3.70 & 5.74 & 4.85 & 7.62 & 3.70 \\
Non-poor & $11.88(3.21)$ & $13.38(2.33)$ & $12.51(2.58)$ & $11.40(3.08)$ & $13.97(1.97)$ & $11.88(3.21)$ \\
\hline
\end{tabular}

Source: Computed using Table 1 and Table 2. 
The ratio of non-poor to poor per capita consumption of each fuel in each studied year is given in parentheses. Note that in all the 22 (out of a total of 24) cases (year-fuel-' type of area' combination) of non-poor per capita fuel consumption being greater than per capita fuel consumption by the poor, the mentioned ratio is significantly greater than 1. To illustrate, it varies between 1.15 and 3.21 for the 11 cases in rural areas and between 1.1 and 3.21 in urban areas. Moreover, in rural areas as many as 4 out of the 11 cases correspond to a ratio greater than 2.15 and 10 cases correspond to a ratio greater than 1.2. In the case of urban areas, 7 of the 11 ratios greater than 1 are in excess of 1.4. Nor is there any common observable trend for the ratio to decline over time and thus indicate any tendency for the ratio to approach 1 or even go below that value. In rural areas a monotonically declining trend is only observed for one (firewood) out of the four studied fuels. In urban areas a monotonically declining trend is not observed for any of the fuels.

It must be conceded though that in the case of all four fuels the ratios observed for the rural areas are lower in the terminal year than in the initial year; however, the lack of monotonicity in regard to three of these fuels makes it impossible for us to even speculate about the ratios approaching 1 in the foreseeable future, especially when three of the ratios in the final year exhibit values of 1.26 (firewood), 1.24 (charcoal) and 2.58 (coal) respectively, which are all significantly greater than 1 . The picture is quite different in the urban areas as three out of the four fuels exhibit ratios which are greater in the final year than in the initial year, the only exception being coke for which the value of the ratio is 1.15 in the last year. Thus, the possibility of the ratios approaching a value less than or equal to 1 is in general very bleak in the urban case.

Our study, therefore, indicates that the Brundtland hypothesis of poverty impacting the environment adversely does not hold even if we consider the consumption of dirty fuels by the 'poor' as well as the 'non-poor'. Actually in more than $90 \%$ of the cases, we get results exactly the opposite of what the hypothesis predicts i.e. the non-poor consume more dirty fuel per capita than the poor. A question arises as to whether this phenomenon is a combination of (a) paucity of clean fuels in India and (b) greater consumption of energy by the non-poor; or alternatively, a combination of (c) almost comparable access of the poor and the non-poor to clean fuels and factor (b). To answer this question we turn to a study of consumption of clean fuels across the Indian expenditure distribution. The study reveals that it is the second mentioned combination which is the plausible reason.

Table 5 shows that there is a monotonic increase in per capita consumption of both LPG and electricity with expenditure, the only exception being the slightly lower per capita consumption in the third quintile as compared to the second quintile in rural India in 1999-00. Table 6 shows clean fuel consumption of an average household to be strictly monotonically increasing with expenditure in both rural and urban areas in all years.

Table 7 shows that the 'poor' consumed vastly less LPG and electricity on a per capita basis than the 'non-poor' in both rural and urban areas in all the studied periods. It should be noted though that the consumption of both fuels by the 'poor' is higher in the terminal period, 2011-12 as compared to the initial period, 1987-88. Some interesting findings are as follows:

(i) In regard to LPG consumption in rural areas, the ratio of per capita non-poor consumption to consumption by the poor declined drastically from 2.24 and stabilized in the region of 1.24-1.27 in the subsequent periods; this decline is much larger than the net decline of 0.1 from the initial to the terminal period in the case of urban areas though the urban ratio was not that high to begin with at 1.46 in the initial period. Given that the consumption expenditure and hence the scale of consumption of the non-poor is much higher than that of the poor, the energy requirements of the former is much greater than that of the latter. Hence, we can conclude that proportion of the energy requirement met by the non-poor from LPG is surely not significantly more than that for the poor and could even be less.

(ii) In regard to electricity consumption the disparity, as measured by the ratio of per capita consumption of the non-poor to the poor, widens in both rural and urban areas over time. Yet even here the ratios in the terminal period in the rural and urban areas are not very large at 1.94 and 2.36 respectively. 
Table 5. Expenditure quintile wise per capita consumption ( $\mathrm{kg} /$ month for $\mathrm{lpg}$ and $\mathrm{kwh} / \mathrm{month}$ for electricity) of clean fuels across time in rural and urban India (Quintile 1 is the poorest quintile)

\begin{tabular}{|c|c|c|c|c|c|c|}
\hline \multirow[b]{2}{*}{ Quintile } & \multicolumn{3}{|l|}{ Rural } & \multicolumn{3}{|l|}{ Urban } \\
\hline & 1987-88 & 1999-00 & 2011-12 & $1987-88$ & 1999-00 & 2011-12 \\
\hline \multicolumn{7}{|c|}{$L P G$} \\
\hline 1 & 0.4 & 1.3 & 1.3 & 1.1 & 1.6 & 1.6 \\
\hline 2 & 0.8 & 1.8 & 1.4 & 1.3 & 1.8 & 1.9 \\
\hline 3 & 1.0 & 1.7 & 1.6 & 1.6 & 2.2 & 2.2 \\
\hline 4 & 1.5 & 2.0 & 1.9 & 1.8 & 2.4 & 2.5 \\
\hline 5 & 2.0 & 2.6 & 2.3 & 2.2 & 3.2 & 3.1 \\
\hline \multicolumn{7}{|c|}{ ELECTRICITY } \\
\hline 1 & 3.0 & 5.7 & 7.3 & 4.0 & 7.1 & 8.8 \\
\hline 2 & 4.0 & 7.5 & 9.8 & 5.1 & 9.4 & 12.8 \\
\hline 3 & 5.1 & 9.3 & 12.8 & 6.8 & 12.1 & 16.4 \\
\hline 4 & 6.6 & 11.9 & 16.6 & 9.4 & 16.3 & 23.3 \\
\hline 5 & 9.3 & 18.1 & 25.8 & 19.3 & 45.8 & 45.3 \\
\hline
\end{tabular}

Source: Computed using Table 1 and 2.

Table 6. Expenditure quintile wise consumption per household ( $\mathrm{kg} /$ month for lpg and kwh/month for electricity) of clean fuels across time in rural and urban India

\begin{tabular}{|c|c|c|c|c|c|c|}
\hline \multirow[b]{2}{*}{ Quintile } & \multicolumn{3}{|c|}{ Rural } & \multicolumn{3}{|c|}{ Urban } \\
\hline & 1987-88 & 1999-00 & 2011-12 & 1987-88 & 1999-00 & 2011-12 \\
\hline \multicolumn{7}{|c|}{$L P G$} \\
\hline 1 & 2.2 & 7.2 & 7.2 & 6.1 & 8.8 & 8.8 \\
\hline 2 & 4.8 & 10.8 & 8.4 & 7.8 & 10.8 & 11.4 \\
\hline 3 & 6.6 & 11.2 & 10.6 & 10.6 & 14.5 & 14.5 \\
\hline 4 & 10.2 & 13.6 & 12.9 & 12.2 & 16.3 & 17 \\
\hline 5 & 13 & 16.9 & 15 & 14.3 & 20.8 & 20.2 \\
\hline \multicolumn{7}{|c|}{ ELECTRICITY } \\
\hline 1 & 16.5 & 31.4 & 40.2 & 22 & 39.1 & 48.4 \\
\hline 2 & 24 & 45 & 58.8 & 30.6 & 56.4 & 76.8 \\
\hline 3 & 33.7 & 61.2 & 84.5 & 44.9 & 79.9 & 108.2 \\
\hline 4 & 44.9 & 80.9 & 112.9 & 63.9 & 110.8 & 158.4 \\
\hline 5 & 60.5 & 117.7 & 167.7 & 125.45 & 297.7 & 294.5 \\
\hline
\end{tabular}

Source: Computed from Table 1 and Table 5.

Table 7. Average per capita consumption ( $\mathrm{kg} /$ month for lpg and $\mathrm{kwh} / \mathrm{month}$ for electricity) of clean fuels of the poor and non-poor in rural and urban India across time

\begin{tabular}{lcccccc}
\hline & \multicolumn{3}{c}{ RURAL } & \multicolumn{3}{c}{ URBAN } \\
\cline { 2 - 7 } & $1987-88$ & $1999-00$ & $2011-12$ & $1987-88$ & $1999-00$ & $2011-12$ \\
\hline Poor & 0.67 & 1.7 & 1.5 & 1.3 & 1.9 & 1.9 \\
Non-poor & $1.5(2.24)$ & $2.1(1.24)$ & $1.9(1.27)$ & $1.9(1.46)$ & $2.3(1.21)$ & $2.6(1.36)$ \\
\hline \multicolumn{7}{c}{ LPG } \\
\hline Poor & 3.9 & 7.3 & 9.4 & 5 & 9.1 & 11.9 \\
Non-poor & $7(1.79)$ & $13.1(1.79)$ & $18.3(1.94)$ & $11.8(2.36)$ & $24.5(2.69)$ & $28.2(2.36)$ \\
\hline
\end{tabular}

Source: Computed using Table 1 and Table 5.

\section{Conclusions and Policy Implications}

The Brundtland Commission Report gave birth to a hypothesis that poverty is a major cause of environmental degradation. This hypothesis was backed by major formal think tanks and organizations and was based on the hypothesis that the wealth and income constraints faced by the poor compel them to exploit natural capital and consume dirty fuels. Gradually however a counter view emerged which argued that the poor do exhibit 
significant tendencies which lower environmental and resource degradation: lower demand for gasoline, lower power to exploit sources of natural capital, and low levels of wealth compelling them to engage in practices that promote resource conservation such as rag picking and scrap collection.

The qualitative arguments by the Brundtland School and the counter school only serve to show that in reality the Brundtland hypothesis might or might not be true. In this paper we analyze household data from the National Sample Survey of India for consumption of four carbon emitting dirty fuels -- firewood, charcoal, coal and coke - and get the surprising result that the household consumption and per capita consumption of dirty fuels is almost always significantly lower among the poor as compared to the non-poor.

The greater per capita consumption of dirty fuels by the non-poor comes as a big surprise given that these households in theory should have much better access to clean fuels such as LPG and electricity for lighting, cooking and heating by virtue of their greater incomes. While we do find that the non-poor consume more LPG and electricity per capita than the poor the ratios of per capita non-poor consumption to consumption by the poor are not very large, starting from levels of 2.24 (1.79) and 1.46 (2.36) respectively in the case of LPG (Electricity) in rural and urban areas in the initial studied year (1987-88) and ending at $1.27(1.94)$ and $1.36(2.36)$ in the terminal year (2011-12).

Given the above findings, the larger scale of per capita consumption of dirty fuels by the non-poor as compared to the poor is best explained on the basis of the larger fuel requirements of the non-poor not being met adequately by the access enjoyed to clean fuels. For example, in the case of LPG there is rationing which puts a cap on the access by the non-poor and subsidization which enables access by the poor. This would imply that it is quite possible that larger fuel requirements for cooking of the non-poor, given their higher income, get translated into greater use of dirty fuels. In regard to electricity, newspaper reports in 2018 indicate average power outages of 5 to 7 hours a week. Common sense would indicate that the power outages would occur mostly in the peak or near peak hours, the very hours in which we would expect the disparity between the requirements of the non-poor and the poor to be higher. If that is the case, this channel also explains why the non-poor can take significant recourse to the use of dirty fuels for lighting, heating etc.

More research should be conducted to understand the reasons for this surprising finding for dirty fuel consumption from NSS data - for example, ascertaining the allocation of dirty fuels to different types of uses such as cooking, lighting and heating by different income classes of households. Nevertheless, the finding points to a significant implication for policy: poverty alleviation on its own will not probably make a dent on environmental degradation such as that which depletes the natural resource base or pollutes the air.

Thus, while poverty alleviation is desirable for many reasons such as a better standard of life for those currently below the poverty line, it is not a panacea for environmental problems. The tendency to degrade the environment might to an extent be lowered by economic growth as environmental quality can be thought of as a normal good though this trend can be countered by the tendency for economic growth to be powered by pollution generating fuels. Thus, the net resulting beneficial impacts on the environment, if any, might not be large enough to prevent the environment from going down the slippery slope of decline.

The movement from poverty to affluence can be seen as a movement along the inverted U shaped Environmental Kuznets Curve. If the poor are shown as located on the early part of the upward sloping segment their ascent to higher incomes will be marked by a higher contribution to environmental degradation unless the level of income attained after coming out of poverty reaches very high levels. But that might not happen in the foreseeable future for the poor in developing countries. An active program to change the attitudes of the people and promote greener practices; and institute pro-environment changes at the macro level such as the development of good public transport systems all over the country seems to be the only solution.

\section{Acknowledgements}

A useful comment by Devashish Mitra on a short article based on an earlier version of the paper helped to add value to this version.

\section{References}

Cuaresma, J. C. et al. (2018). Will the Sustainable Development Goals be fulfilled? Assessing present and future global poverty. Palgrave Communications, 4, 29. https://doi.org/10.1057/s41599-018-0083-y

Duraiappah, A. K. (1996). Poverty and Environmental Degradation: A Literature Review and Analysis. CREED Working Paper Series No $8 . \quad$ Retrieved from https://www.prem-online.org/archive/17/doc/creed08e.pdf 
Duraiappah, A. K. (1998).Poverty and Environmental Degradation: A Review and Analysis of the Nexus. World Development, 26(12), 2169-79. https://doi.org/10.1016/S0305-750X(98)00100-4

Furedy, C. (1984). Survival strategies of the urban poor-scavenging and recuperation in Calcutta. GeoJournal, 8(2), 129-136. https://doi.org/10.1007/BF00231491

GlobalPetrolPrices.com. (Website). Gasoline Consumption Per capita around the world. Retrieved from https://www.globalpetrolprices.com/articles/52/

Kharas, H., Kristofer, H., \& Martin, H. (2018). The start of a new poverty narrative. Retrieved from https://www.brookings.edu/blog/future-development/2018/06/19/the-start-of-a-new-poverty-narrative/

Medina, M. (2000). Scavenger cooperatives in Asia and Latin America. Resources, Conservation and Recycling, 31(1), 51-69. https://doi.org/10.1016/S0921-3449(00)00071-9

Medina, M. (2001). Scavenging in America: back to the future? Resources, Conservation and Recycling, 31(3), 229-240. https://doi.org/10.1016/S0921-3449(00)00082-3

OECD Data (Website). Retrieved from https://data.oecd.org/agroutput/meat-consumption.htm

Office for National Statistics, United Kingdom (Website). Retrieved from https://www.ons.gov.uk/peoplepopulationandcommunity/populationandmigration/populationestimates/bulle tins/annualmidyearpopulationestimates/2013-12-17

Planning Commission, Government of India. (June 2014). Report of the Expert Group to Review the Methodology for Measurement of Poverty. Retrieved from https://www.indiaenvironmentportal.org.in

Ranjan, R., \& Sudershan, S. (2017). Energy deprivation of Indian households: evidence from NSSO data. Munich Personal RePEc Archive, Working Paper. Retrieved from https://mpra.ub.uni-muenchen.de/83566/1/MPRA_paper_83566.pdf

Ravnborg, H. M. (2003). Poverty and Environmental Degradation in the Nicaraguan Hillsides. World Development, 31(11), 1933-1946. https://doi.org/10.1016/j.worlddev.2003.06.005

Reardon, T., \& Stephen, A. V. (1995). Links Between Rural Poverty and the Environment in Developing Countries: Asset Categories and Investment Poverty. World Development, 23(9), 1495-1506. https://doi.org/10.1016/0305-750X(95)00061-G

Report of the World Commission on Environment and Development. (1987). Our Common Future. Retrieved from https://www.un-documents.net/our-common-future.pdf

Rodriguez-Oreggia, E., \& Rigoberto, A. Y. G.(2014). Income and Energy Consumption in Mexican Households. World Bank Policy Research Working Paper 6864. Retrieved from https://www.researchgate.net/publication/262639788_Income_and_Energy_Consumption_in_Mexican_Hou seholds

Rukmini, S., \& Sivaraman, S. (2014). A look at how income affects consumption habits. Retrieved from https://www.thehindu.com/data/a-look-at-how-income-affects-consumption-habits/article6180214.ece

Satterthwaite, D. (2003). The Links between Poverty and the Environment in Urban Areas of Africa, Asia, and Latin America. The ANNALS of the American Academy of Political and Social Science, 590, 73-92. https://doi.org/10.1177/0002716203257095

Scherr, S. J. (2000). A downward spiral? Research evidence on the relationship between poverty and natural resource degradation. Food Policy, 25(2000), 479-498. https://doi.org/10.1016/S0306-9192(00)00022-1

$\begin{array}{lllll}\text { Statistics } & \text { Times. } & \text { (website). } & \text { Retrieved }\end{array}$ http://statisticstimes.com/population/countries-by-population-density.php

United Nations. (2017). World Population Prospects: The 2017 Revision. Retrieved from https://www.un.org/development/desa/publications/world-population-prospects-the-2017-revision.html

Williams, A. G., Audsley, E., \& Sandars, D. L.(2006). Determining the environmental burdens and resource use in the production of agricultural and horticultural commodities. Main Report, Defra Research Project IS0205, Bedford: Cranfield University and Defra. Retrieved from https://www.researchgate.net/publication/265084052_Determining_the_environmental_burdens_and_resour ce_use_in_the_production_of_agricultural_and_horticultural_commodities_Defra_project_report_IS0205

World Bank Data. (website). Retrieved from https://data.worldbank.org/indicator/NY.GDP.PCAP.PP.KD 
World Health Organization. (2003). Report on India in World Health Survey, 2003. Retrieved from http://www.who.int/healthinfo/survey/whsind-india.pdf

World Poverty Clock (website). Retrieved from https://worldpoverty.io/

\section{Notes}

Note 1. The per capita incomes used by us are those estimated by the World Bank for 2017. The measure of income used is GDP per capita at purchasing power parity (constant 2011 international dollars). In other words, the unit of per capita income measurement is the same across countries and equals the purchasing power of the US dollar in 2011 in the US. The data used is from the World Bank Data website.

Note 2. Statistics Times Website: This website presents World Bank data on population density for 2013.

\section{Copyrights}

Copyright for this article is retained by the author(s), with first publication rights granted to the journal.

This is an open-access article distributed under the terms and conditions of the Creative Commons Attribution license (http://creativecommons.org/licenses/by/4.0/). 